\title{
Effects of Emotion and Perspective on Remembering Events: An Eye-Tracking Study
}

\author{
Çiğdem Gülçay \\ Uludağ University
}

\author{
Banu Cangöz \\ Hacettepe University
}

\begin{abstract}
The main objective of this study is to investigate the effects of the emotional content of an event and participants' perspective on the memory and eye-tracking measurements for central and peripheral details. The data have been collected from 130 undergraduate male students (18- 33 ages). Three series of seven different emotional thematic photographs (positive, negative, neutral) were used. Participants were subjected to only one of the three series, either in his own perspective condition or observer perspective condition. During the presentation of thematic photograph series participants' eye movements were recorded. All analysis for memory and eye-tracking measurements were carried out with 3 (Emotional Content: Positive, Negative, Neutral) X 2 (Participants' perspective: Own perspective, observer perspective) between-subjects factorial ANOVA. The results indicated that although central and peripheral details took almost equal attention in both negative and neutral events, only details of the negative event was remembered better. In addition, when compared to negative and neutral events participants looked longer at positive event's central details as well as peripheral details, only details of negative event were remembered better. Consequently, memory enhancement effect occured only in negative emotional event both for central and peripheral details, even though participants paid less or equal attention these details. In addition to effects of emotion, it was seen that like autobiographical memory (Nigro and Neisser, 1983) participants' perspective has also an effect on event memory and attention measured by eye-tracking. According to eye-tracking results looking with his own perspective to the event causes narrowing of attention while looking with observer's perspective to event causes extending of attention. In memory results it was seen that participants in his own perspective condition remembered central details better than participants in the observer condition. In conclusion, it is observed that enhanced memory for negative emotional event can occur independently of attention, so it could be said that attention is not sufficient by itself to remember an event with details, emotional dimension of the event has a decisive role. Additionally, perspective have an effect on attention as well as event memory.
\end{abstract}

Keywords: emotion, perspective, event memory, free recall, attention, eye-tracking

\section{Introduction}

We face many events in our everyday life. Some of them are events that happen to us while others are just events that we witness or watch. Among them, some we can recall with a lot of details after a long time while some others we forget in a short time.

Remembering the details of a particular event is defined as "event memory". Events examined in this context, are the ones, which occur in a particular time and place and last a few minutes or hours, but days or weeks (Conway, 1996).
Event memory can be examined as a part of various memory types like autobiographical memory, flashbulb memory, and eyewitness memory. Remembering the details of event itself is important for event memory.

Several laboratory studies on event memory have used thematic slide series, short films or real life events of emotional events (Loftus and Burns, 1982; Heuer and Reisberg, 1990; Christianson and Loftus, 1991; Burke, Heuer and Reisberg, 1992; Loftus, Loftus and Messo, 1998; Brown, 2003; Hope and Wright, 2007; Lanciano and Curci, 2011).

One of the fundamental findings related to the event memory, is that emotional events are remembered better 
than the non-emotional ones (Christianson and Loftus, 1991; Burke et al., 1992; D'Argembeau, Comblain and Linden, 2003; Comblain, D'Argembeau and Linden, 2005; Kensinger, Krendl and Corkin, 2006; Kensinger and Schacter, 2006); moreover "not all details of emotional events are equally remembered", as especially in negative emotional events central details are remembered better than peripheral ones (Christianson and Loftus, 1991; Christianson, Loftus, Hoffman and Loftus, 1991; Burke et al., 1992; Wessel, Kooy and Merckelbach, 2000; Hope and Wright, 2007). Although there is a consensus regarding how well central details are remembered in emotional events, research has yielded some contradictory findings on remembering peripheral details, especially in negative emotional events. Besides the studies showing that negative emotions negatively affect the peripheral details to be remembered (Loftus et al., 1987; Berntsen, 2002; Brown, 2003; Hope and Wright, 2007; Kensinger, Garoff-Eaton and Schacter, 2007b; Kensinger, 2009; Talarico, Bernsten and Rubin, 2009; Yegiyan and Yonelinas, 2011; Chipchase and Chapman, 2013), there are some studies which have shown that negative emotions increases the recalling of both central and peripheral details (Heuer and Reisberg 1990; Libkuman, Nichols-Whitehead, Griffith and Thomas, 1999; Laney, Campbell, Heuer and Reisberg, 2004; Lanciano and Curci, 2011). Other studies however have indicated that negative emotions make no differences in terms of recalling peripheral details (Christianson et al., 1991; Wessel et al., 2000; Otani, Libkuman, Widner and Graves, 2007). These different results in remembering the peripheral details of a negative emotional event, may be due to reasons such as the clarity of definition of "peripheral detail", differences in the level of emotional stimulus' arousal, the number of questions that are asked to the participants, and the duration of the tests. So, these factors should be all considered in the evaluation of results.

There are different approaches to explain the relationship between the emotion and the type of detail to be remembered. One of them is the attentional narrowing hypothesis (Christianson, 1992). According to this hypothesis, emotional arousal directs the attention towards the central rather than towards the peripheral characteristics of an event. As a result, while peripheral details are remembered less, central details are better recalled because they are attended more (Safer, Christianson, Autry and Österlund, 1998; Wessel et al., 2000; Brown, 2003; Blank, 2011; Riggs, McQuiggan, Farb, Anderson and Ryan, 2011). An- other idea that supports the attentional narrowing hypothesis is "weapon focus effect", according to which individuals who witness a crime, focus solely on the gun and as they remember the gun, they do not remember other details of the environment like the perpetrator's face (Loftus et al., 1987).

Based on the assumption that different emotional events reflect different evaluation patterns, some researchers have suggested that the memory related to central and peripheral details in emotional events shows different patterns in positive and negative emotional events. It is claimed that negative emotions narrow the scope of attention, whereas positive emotions extend it (Talarico, Berntsen and Rubin, 2009; Fredrickson and Branigan, 2005). According to this claim, central details are better remembered than peripheral ones in negative emotional events because of narrowing of the attention; nonetheless this principle does not apply in positive emotional events as extending the scope of attention leads one to remember equally well both peripheral and central details (Berntsen, 2002; Libkuman, Stabler and Otani, 2004; Talarico et al., 2009; Yegiyan and Lang, 2010; Yegiyan and Yonelinas, 2011).

Most researchers agree that eye movements reflect visual attention (Christianson et al, 1991; Loftus, 1972; Loftus et al., 1987). Eye-tracking devices provide objective and quantitative data about where, at what frequency, and for how much time people look at stable or moving visual stimulus. Towards this end, eye-tracking devices make important scientific contributions to understanding the relation between emotion-attention and memory. Therefore, they provide to researchers the opportunity to test whether participants remember better due to the fact that they pay more attention to a stimulus or whether they remember better due to emotional attribute of the stimulus.

According to studies of eye movement, viewers look longer at emotional pictures than at neutral ones (Calvo and Lang, 2004; Nummenmaa, Hynönä and Calvo, 2006; Chipchase and Chapman, 2013). However, there are two conflicting findings for positive and negative pictures. While Chipchase and Chapman (2013) indicated that negative pictures are viewed longer than positive ones, whereas Humphreys, Underwood and Chapman (2010) indicated the exact opposite pattern.

In negative emotional events, while central details are longer viewed than neutral ones (longer fixation duration 
and/or more fixation counts), peripheral details are viewed less (shorter fixation duration or less fixation counts). In other words, it was seen that the attention gets narrow in negative emotional events (Loftus et al., 1987; Christianson et al, 1991; Wessel et al., 2000; White, 2007; Blank, 2011; Chipchase and Chapman, 2013). At the same time, in positive emotional events more and longer fixations to peripheral details were detected compared to negative or neutral stimulus. In other words, it was seen that the attention extends in positive emotional events (Wadlinger and Isaacowitz, 2006). These results of eye-tracking studies support the attentional narrowing hypothesis (Christianson, 1992) which claims that attention gets narrow in negative emotional stimulus or events. It also provides support to the broaden-and-built hypothesis (Fredrickson, 1998) which claims that the scope of attention extends in positive stimulus or events.

Some eye-tracking studies, which have examined the role of attention in the relationship between emotion and memory suggest that along with differences in attention allocation, the effect of emotion on cognitive processes is also an important factor in remembering emotional events. Emotion-provoking stimulus helps remembering through directing the attention and enhancing coding (Christianson et al, 1991; Blank, 2011). An eye-tracking study conducted by Christianson and colleagues (1991) showed that despite the fact that participants looked equally at central details of neutral and negative events, they remembered central details of negative events better than neutral events. Humphreys, Underwood and Chapman (2010) examined the role of attention in emotional memory enhancement by means of eye-tracking technique. They found that positive photographs got more attention than the negative ones, but in recognition test, memory enhancement occurred only in negative photographs. In another study by Riggs and colleagues (2011) it was examined the role of attention in remembering the details of emotional stimulus. These authors found attention partially mediate the relation between memory and emotion. In conclusion, Riggs et al. (2011) argued that differences in remembering central and peripheral details are not solely a result of differences in overt attention allocation but there may be a direct effect of emotion on the memory through cognitive mechanisms (deep process) or through specialized neuromodulation mechanisms (amygdala).

The encoding type of the event also affects how the event will be remembered. According to the self-reference effect, people tend to remember better objects that are relevant with themselves than events that are irrelevant to them (Rogers, Kuiper and Kirker, 1977; Symons and Johnson, 1997; Serbun, 2009). If people remember better events that are relevant with them, it is logical to infer that they may also remember equally well irrelevant events in which they empathize with the main character. Findings showing that perspective-taking causes different effects on the memory are generally obtained from autobiographical memory studies. Nigro and Neisser (1983), investigated effect of perspective types on the autobiographical memory. According to this study, in field perspective, the person remembers the event like in original condition with his/her own perspective, in observer perspective, the person remembers the event just like an outer observer, who witnessed from outside. Emotional events are remembered with more field perspective, when compared to non-emotional events (Nigro and Neisser, 1983; D'Argembeau et al., 2003; Berntsen and Rubin, 2006; Sayar and Cangöz, 2013).

Both event memory and eye-tracking studies conducted so far examined emotional based differences in remembering, but effects of participants' perspective on event memory or eye-tracking have not examined yet. In this study, besides the emotional content of event, the effect of participants' perspective in remembering details from emotional events was examined. Changing participants' perspective by instructions may cause difference in remembering.

To sum up, the main aim of this study is to show the relationship between attention, emotion and memory by investigating the effects of the emotional content of an event (positive, negative and neutral) and participants' perspective (own perspective, observer perspective) on the memory (free recall scores) and eye-tracking (total fixation duration, fixation count) of central and peripheral details. The research hypotheses are as follows:

1) Free recall for positive and negative emotional events will be higher than neutral events.

2) Total fixation duration and fixation count for positive and negative emotional events will be higher than neutral events.

3) Free recall in the own perspective condition will be higher than in the observer condition. 
4) Total fixation duration and fixation count in the own perspective condition will be higher than in the observer condition.

5) Free recall for positive and negative emotional events will be higher in the own perspective condition than in the observer condition.

6) Total fixation duration and fixation count for positive and negative emotional events will be higher in the own perspective condition than in the observer condition.

\section{Methods}

\section{Participants}

130 male undergraduate students, aged between 18 and $33(\mathrm{M}=21.07, \mathrm{SD}=1.82)$ volunteered to participate in the study. All participants had normal or corrected to normal visual acuity. 120 were right-handed, 6 were left-handed, and 4 were capable of using both hands.

Participants were shown women and men in thematic photographs. In order to control the potential bias effects due to participant's gender, gender was kept constant at one level.

Data from participants, who did not meet the criteria were excluded from the study. In particular, we dropped data from 4 persons who were found to be color-blind, 3 persons, who declared that they had neurological or psychiatric problems, 2 persons, who used drugs that could affect cognitive functioning, 19 persons, who failed emotion or perspective manipulations, and 38 persons whose eye-tracking data quality were below the $70 \%$ threshold that we a priori had set. Consequently, our analyses were based on 102 and 92 participants from whom we had, respectively memory-related and eye-tracking data.

\section{Materials}

Thematic Photograph Series. In the study, three different emotional thematic photograph series (positive, negative, and neutral) were used each of which consisted of seven digital and colored static and real-life scenes (see Appendix 1). The first three and the last three photographs were all the same but only the $4^{\text {th }}$ photograph (target) was different in each thematic series. The target photographs in the three different conditions depicted a scene from a "birth (positive theme), "death" (negative theme) and "everyday home state" (neutral theme). Photographs were prepared by Necla Rüzgar Kayıran, a faculty member of Fine Arts. Emotional valences of target photographs were tested by a pilot study (for neutral photograph $\mathrm{M}=2.93, \mathrm{SD}=0.78$; for positive photograph $\mathrm{M}=4.37, \mathrm{SD}=0.59$; for negative photograph $\mathrm{M}=1.30, \mathrm{SD}=0.54$; in the 5-point Likert type scale 1 refers to very unpleasant and 5 refers to very pleasant).

Visual features like colors, luminance, contrast, complexity and other contextual features like clothes of persons, number of persons, decoration of location etc. in the photos were kept equal as much as possible in the different emotional conditions.

Participants viewed only one of the thematic photograph series (i.e., positive, negative or neutral), either in their own-perspective condition or the observer-perspective condition. So that, all independent variables were manipulated between groups.

Free Recall Form. Free Recall Form consisted of questions aiming to address participants' focus on the central and peripheral details in the thematic photograph series. For positive, negative and neutral photographs, different Free Recall Form had been created. Each of the forms consisted of 20 questions. Eight of the questions in the Free Recall Form were exactly the same, while 12 of them were equivalent with each form. Items, which were directly (i.e., first-degree) related to an emotional event, were defined as central details, whereas items which were not directly related to an emotional event were defined as peripheral details. The Free Recall Form contained 20 questions, 10 questions about central details (e.g., "What was young man doing in the target photograph?", "How many people were there in the room in the target photograph?" etc.) and 10 questions about peripheral details (e.g., "How many pictures were there on the wall in the target photograph?", "What was the color of the wall in the target photograph? etc.) (for detailed information see Appendix 3).

The pilot study with 25 male undergraduate students was conducted to create the answer key used for evaluation of the Free Recall Form. In the pilot study, positive, negative and neutral photographs were displayed to participants one by one through a computer screen and participants were asked to answer the questions in the Free Recall Form by examining the photographs they saw on the screen without a time limitation. A list of acceptable answers for each question was created based on the answer frequencies in the pilot study. According to these acceptable answers, participant's correct answers were given 1 point and wrong 
answers were given 0 point in the main study. Then, central and peripheral points were formed in the respect to these points.

Eye-Tracking Device T120 (Tobii Eye-Tracker T120). To collect data of participants' eye movements, we used the Tobii eye-tracking device model T120. Tobii T120 device was connected with eye-tracking server and a $1280 \times 1024$ pixel resolution 17" TFT monitor. The data collection frequency was at $120 \mathrm{~Hz}$ with a feature of tracking binocular (two eyes); eye movements were recorded with a $0.5^{\circ}$ error rate.

Eye-tracking device can reliably and accurately record eye-movements even from participants who wear glasses or lenses. Hence, participants who were wearing glasses or contact lenses were permitted to wear them during testing as this did not interfere with eye-tracking data collection procedure. Calibration was set for each participant separately.

The base for calibration level was set to $70 \%$ (the percentage of data quality was calculated automatically by
Gülçay, C. \& Cangöz, B. (2016) Effects of Emotion and Perspective on Remembering Events: An Eye-Tracking Study

Tobii T120 model eye-tracking device), so that participants who had lower calibration scores were removed from the study.

In this study, eye movements were recorded for presentation of each thematic series but only the eye-tracking data related with the target photographs were analyzed. Initially, Area of Interests (AOI's) for each target photograph in thematic photograph series were identified in Tobii Studio program. Two areas of interests (AOIs) were determined for eye-track metrics: (a) "central" AOI's (central details), (b) "peripheral" AOI's (peripheral details). Central AOI's, which details are directly (first-degree) related to the emotional event (Main character was existed and marked by AOI in all themes. For example in the negative theme the main character and the dead man were marked by central AOI's). Peripheral AOI's were those which were not semantically related to the emotional event (etc., all characters other than main characters, pictures on the wall, TV, floor lamp etc. marked by peripheral AOI's) (see Figure 1). In the neutral photograph, since there was no emotional priority among characters, therefore all char-

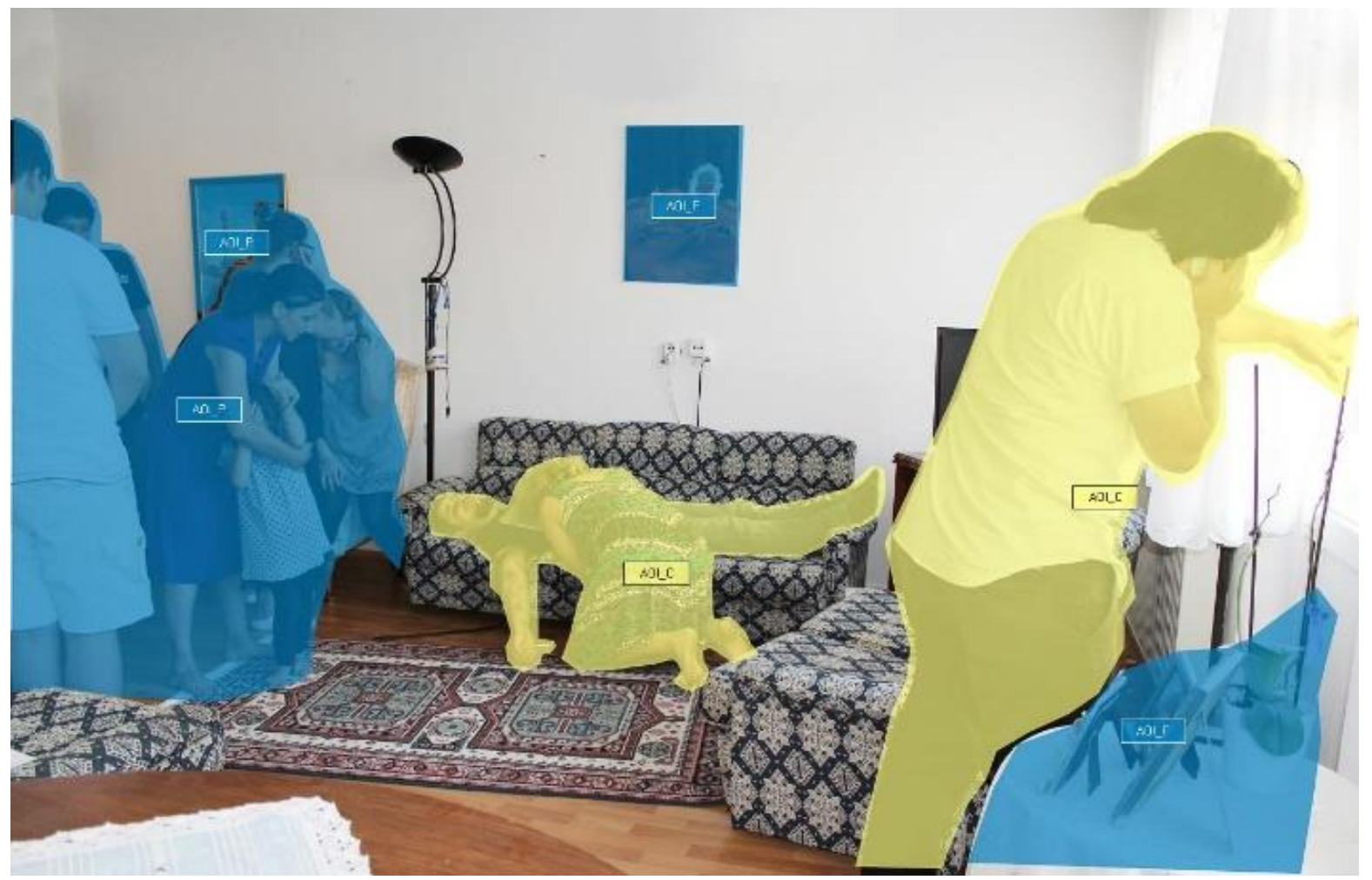


acters were defined as central AOIs while inanimate objects were defined as peripheral AOIs. Other areas except of central and peripheral AOI's were considered as a background in all target photographs. Background areas were not included in the analysis and were not marked by AOI. AOI's area sizes differed to each other but they were kept equal in the three different theme conditions. AOI's were equalized in terms of percentage of their area sizes and measurements of each eye-track metrics were calculated again based on this standardization.

Ishihara Color Blindness Test. Ishihara Color Blindness Test is mostly used to identify color blindness. The test is highly sensitive to red-green color vision defects (\% 93) (Ishihara, 1990; Birch 1997). Ishihara Color Blindness Test was used to identify whether participants have color blindness.

\section{Procedure}

The experiment was applied individually and took approximately 20 minutes. Participants were informed about the study and signed an informed consent before the application. Then, Ishihara Color Blindness Test was applied. Once the Ishihara Color Blindness test was over, participants were seated in front of Tobii T120 model eye-tracking device. Their eyes were positioned approximately 60$65 \mathrm{~cm}$ away from the computer screen. Comfortable seating was arranged for all participants, while keeping their heads fixed across the screen. Visual angle of the screen was $30^{\circ} \times 27^{\circ}$ and visual angle of the photographs were $14^{\circ}$ $\mathrm{x} 16^{\circ}$. Before starting the experiment, calibrations were performed individually in eye-tracking device for each participant.

The instructions were given both orally by the experimenter and written on the screen of the eye-tracking device. In the "his own perspective" condition, participants were told that a series of thematic, photographs with a subject would be shown, and that they should keep tracking what was happening by looking at these photos until the end. The participants were asked to empathize themselves with the main character, when they were doing this. Before the presentation of the series, participants were shown three photographs taken from the front, the side and the back of the main character (young guy), with whom they should empathize with. In contrast, in the "observer perspective" condition, participants were told that they would be shown a series of thematic, photographs with a subject, and that they should keep tracking what was happening by passively looking at these photos until the end. Participants in both conditions were not told that a memory test would be conducted.

After these instructions, presentation of thematic photograph series was initiated. Presentation of the photograph series were made from the screen of Tobii T120 eyetracking device. Each photograph remained on the screen for 8 seconds and the time of switching between two consecutive photos was 1 second. Participants were assigned to only one of the thematic photograph series; (i.e., positive, negative or neutral) either in the "own perspective" condition or the "observer perspective" condition.

After the presentation of thematic photograph series, participants performed Porteus Maze Tests of numbered cards of $1,3,4,5,6,7,8,9,10,11$ as a distractor task. Then, the participants answered to the Free Recall Form which consisted questions about the central and the peripheral details related to the target photographs. To check our manipulation, we asked the participants a) three openended questions to control whether the target images created the desired emotions to the participants, and another b) three open-ended questions to control whether the own versus observer perspective manipulation created the desired effects (for detailed information see Appendix 4).

\section{Results}

All analysis for memory and eye-tracking measurements were carried out by 3 (Emotional Content: Positive, Negative, Neutral) X 2 (Participants' perspective: Own perspective, observer perspective) between-subjects factorial ANOVA. Post hoc comparisons were run with Bonferroni correction for significant main and interaction effects. In post hoc comparisons Bonferroni test was used for equal variances and Games-Howell test was used for nonequal variances.

\section{Memory Results}

Central details. According to ANOVA results there is significant main effect of emotional content $\left(F_{(2,96)}=19.01\right.$, $\left.p<.001, \eta_{\mathrm{p}}{ }^{2}=0.28\right)$ and of participants' perspective $\left(F_{(1,}\right.$ $\left.{ }_{96)}=8.08, p<.01, \eta_{\mathrm{p}}{ }^{2}=0.08\right)$ and a significant interaction effect between emotional content and participants' perspective $\left(F_{(2,96)}=3.83, p<.05, \eta_{\mathrm{p}}{ }^{2}=0.07\right)$ on remembering central details of the event. Means, standard deviations and post hoc comparisons are shown at Table 1. 
Table 1

Summary of Memory Results

\begin{tabular}{|c|c|c|c|c|c|}
\hline \multirow{2}{*}{\multicolumn{2}{|c|}{$\begin{array}{l}\text { Main and Interaction } \\
\text { Effects }\end{array}$}} & \multicolumn{2}{|c|}{ Central Details Free Recall Scores } & \multicolumn{2}{|c|}{ Peripheral Details Free Recall Scores } \\
\hline & & Mean \pm Std. Dev. & Comparisons & Mean \pm Std. Dev. & Comparisons \\
\hline \multicolumn{6}{|c|}{ Emotional Content } \\
\hline \multicolumn{2}{|c|}{ Positive } & $3.35 \pm 1.78$ & & $1.40 \pm 1.14$ & \\
\hline \multicolumn{2}{|c|}{ Negative } & $5.71 \pm 1.79$ & $\begin{array}{l}\text { Negative }>\text { Positive } * * * \\
\text { Negative }>\text { Neutral } * * *\end{array}$ & $2.97 \pm 1.05$ & $\begin{array}{l}\text { Negative }>\text { Positive } * * * \\
\text { Negative }>\text { Neutral } * *\end{array}$ \\
\hline $\mathrm{Ne}$ & tral & $3.88 \pm 1.53$ & & $1.85 \pm 1.35$ & \\
\hline \multicolumn{6}{|c|}{$\begin{array}{l}\text { Participants' } \\
\text { Perspective }\end{array}$} \\
\hline \multicolumn{2}{|c|}{ Own } & $4.73 \pm 1.59$ & Own > Observer $*$ & $2.04 \pm 1.47$ & N.S. \\
\hline \multicolumn{2}{|c|}{ Observer } & $3.81 \pm 2.16$ & & $2.01 \pm 1.24$ & \\
\hline \multicolumn{6}{|c|}{$\begin{array}{c}\text { Emotional Content } * \\
\text { Participants' } \\
\text { Perspective }\end{array}$} \\
\hline \multirow{2}{*}{ Positive } & Own & $4.39 \pm 1.61$ & Own > Observer $*$ & $1.28 \pm 1.23$ & N.S. \\
\hline & Observer & $2.37 \pm 1.34$ & & $1.53 \pm 1.07$ & \\
\hline \multirow{2}{*}{ Negative } & Own & $5.64 \pm 1.60$ & N.S. & $3.21 \pm 1.19$ & N.S. \\
\hline & Observer & $5.76 \pm 1.98$ & & $2.76 \pm 0.90$ & \\
\hline \multirow{2}{*}{ Neutral } & Own & $4.31 \pm 1.30$ & N.S. & $1.88 \pm 1.36$ & N.S. \\
\hline & Observer & $3.50 \pm 1.65$ & & $1.83 \pm 1.38$ & \\
\hline
\end{tabular}

$* * * \mathrm{p}<.001, * * \mathrm{p}<.01, * \mathrm{p}<.05$, N.S. Not Significant

Peripheral details. According to ANOVA results there was a significant main effect only for emotional content $\left(F_{(2,96)}=15.27, p<.001, \eta_{\mathrm{p}}{ }^{2}=0.24\right)$ on remembering peripheral details of the event. Means, standard deviations and post hoc comparisons are shown at Table 1.

\section{Eye-tracking Results}

Central details. One of the eye-tracking metrics which is analyzed is total fixation duration. Total fixation duration is the total time of fixations in seconds within an AOI. According to ANOVA results there was a significant main effect of emotional content $\left(F_{(2,86)}=22.12, \quad p<.001\right.$, $\left.\eta_{\mathrm{p}}{ }^{2}=0.34\right)$ and of participants' perspective $\left(F_{(1,86)}=18.56\right.$, $\left.p<.001, \eta_{\mathrm{p}}{ }^{2}=0.18\right)$ and a significant interaction effect between emotional content and participants' perspective $\left(F_{(2}\right.$, 86) $=3.37, p<.05, \eta_{\mathrm{p}}{ }^{2}=0.07$ ) on total fixation duration on the central details of target photographs. The other eye-tracking metrics which is analyzed is fixation count.
Fixation count is the number of fixations within an AOI. According to ANOVA results there was a significant main effect only for emotional content $\left(F_{(2,86)}=12.26\right.$, $p<.001, \eta_{\mathrm{p}}{ }^{2}=0.22$ ) on participants' fixation counts on the central details of target photographs. Means, standard deviations and post hoc comparisons for eye-tracking metrics are shown at Table 2.

Peripheral details. According to ANOVA results there was a significant main effect of emotional content $\left(F_{(2}\right.$, $\left.{ }_{86)}=4.12, p<.05, \eta_{\mathrm{p}}{ }^{2}=0.09\right)$ and of participants' perspective $\left(F_{(1,86)}=27.01, p<.001, \eta_{\mathrm{p}}{ }^{2}=0.24\right)$ on total fixation duration on the peripheral details of target photographs. According to ANOVA results there was a significant main effect of emotional content $\left(F_{(2,86)}=13.95, p<.001, \eta_{\mathrm{p}}{ }^{2}=0.25\right)$ and of participants' perspective $\left(F_{(1,86)}=15.07, p<.001, \eta_{\mathrm{p}}{ }^{2}=0.15\right)$ on participants' fixation counts on the peripheral details of target photographs. Means, standard deviations and post hoc comparisons for eye-tracking metrics are shown at Table 2. Heat Maps (Total Fixation Counts) of target photographs for each emotional events were added in Appendix 2. 
Journal of Eye Movement Research $9(2): 4,1-19$
Gülçay, Ç. \& Cangöz, B. (2016)

Effects of Emotion and Perspective on Remembering Events:

Table 2

Summary of Eye-Tracking Results

\begin{tabular}{|c|c|c|c|c|c|c|c|c|}
\hline \multirow[b]{3}{*}{$\begin{array}{l}\text { Main and Interaction } \\
\text { Effects }\end{array}$} & \multicolumn{4}{|c|}{ Fixation Duration } & \multicolumn{4}{|c|}{ Fixation Count } \\
\hline & \multicolumn{2}{|c|}{ Central Details } & \multicolumn{2}{|c|}{ Peripheral Details } & \multicolumn{2}{|c|}{ Central Details } & \multicolumn{2}{|c|}{ Peripheral Details } \\
\hline & $\begin{array}{l}\text { Mean (second) } \\
\pm \text { Std. Dev. }\end{array}$ & Comparisons & $\begin{array}{l}\text { Mean (second) } \\
\pm \text { Std. Dev. }\end{array}$ & Comparisons & $\begin{array}{c}\text { Mean } \pm \text { Std } \\
\text { Dev. }\end{array}$ & Comparisons & $\begin{array}{l}\text { Mean } \pm \text { Std } \\
\text { Dev. }\end{array}$ & Comparisons \\
\hline \multicolumn{9}{|l|}{ Emotional Content } \\
\hline Positive & $9.89 \pm 4.12$ & $\begin{array}{r}\text { Positive }>\text { Negative } * * * \\
\text { Positive }>\text { Neutral } * * *\end{array}$ & $4.82 \pm 1.34$ & Positive $>$ Negative $* *$ & $25.86 \pm 10.53$ & $\begin{array}{l}\text { Positive }>\text { Negative } * * * \\
\text { Positive }>\text { Neutral } * *\end{array}$ & $15.04 \pm 4.06$ & $\begin{array}{l}\text { Positive }>\text { Negative } * * * \\
\text { Positive }>\text { Neutral } * * *\end{array}$ \\
\hline Negative & $6.15 \pm 2.33$ & & $3.60 \pm 1.51$ & & $17.95 \pm 6.36$ & & $10.89 \pm 4.35$ & \\
\hline Neutral & $6.02 \pm 1.93$ & & $4.37 \pm 2.37$ & & $17.32 \pm 4.81$ & & $9.62 \pm 4.20$ & \\
\hline \multicolumn{9}{|l|}{$\begin{array}{l}\text { Participants' } \\
\text { Perspective }\end{array}$} \\
\hline Own & $8.34 \pm 3.80$ & Own $>$ Observer $* * *$ & $3.31 \pm 1.55$ & & $21.20 \pm 10.06$ & N.S. & $10.08 \pm 4.49$ & \\
\hline Observer & $6.20 \pm 2.52$ & & $5.07 \pm 1.67$ & Observer $>$ Own $* * *$ & $19.18 \pm 6.26$ & & $13.37 \pm 4.43$ & Observer $>$ Own $* * *$ \\
\hline
\end{tabular}

Emotional Content

Participants'

Perspective

\begin{tabular}{|c|c|c|c|c|c|c|c|c|c|}
\hline \multirow[t]{2}{*}{ Positive } & Own & $12.24 \pm 3.85$ & Own > Observer $* * *$ & $3.89 \pm 1.40$ & N.S. & $28.99 \pm 13.05$ & N.S. & $12.58 \pm 4.32$ & N.S. \\
\hline & Observer & $7.86 \pm 3.25$ & & $5.63 \pm 0.55$ & & $23.15 \pm 7.12$ & & $17.17 \pm 2.30$ & \\
\hline \multirow[t]{2}{*}{ Negative } & Own & $6.67 \pm 2.80$ & N.S. & $2.90 \pm 1.34$ & N.S. & $17.58 \pm 7.37$ & N.S. & $9.27 \pm 4.35$ & N.S. \\
\hline & Observer & $5.56 \pm 1.53$ & & $4.38 \pm 1.30$ & & $18.37 \pm 5.21$ & & $12.70 \pm 3.67$ & \\
\hline \multirow[t]{2}{*}{ Neutral } & Own & $6.89 \pm 1.79$ & N.S. & $3.33 \pm 1.88$ & N.S. & $18.70 \pm 5.08$ & N.S. & $8.79 \pm 4.17$ & N.S. \\
\hline & Observer & $5.27 \pm 1.80$ & & $5.27 \pm 2.44$ & & $16.12 \pm 4.39$ & & $10.34 \pm 4.24$ & \\
\hline
\end{tabular}

$* * * \mathrm{p}<.001, * * \mathrm{p}<.01$, N.S. Not Significant 


\section{Discussion}

This study examined the effects of the emotional content of an event and participants' perspective on their memory and eye-tracking patterns related with central and peripheral details.

\section{Discussion Related with Effects of Emotion}

In this study, emotional memory enhancement effect (Hamann, 2001; Buchanan and Adolphs, 2002; Buchanan, 2007; Baran, Cangöz and Özel Kızıl, 2014) emerged for negative photograph, but not for positive photograph. Although some studies have found positive events/stimulus to be remembered better than neutral ones (D'Argembeaue et al., 2003; Comblain et al., 2005; Kensinger and Schacter, 2006; Yegiyan and Yonelinas, 2011; Chipchase and Chapman, 2013), this was not found in our study as there was no difference in remembering central and peripheral details of positive and neutral events. One of the reason that there is no difference in remembering central and peripheral details of positive and neutral events could be due to neutral photograph evaluated as emotional photograph (positive: peaceful family context or negative: as a boring family context). Indeed, in the pilot study (which was done in order to determine emotional valence of target photographs in thematic photograph series) and in manipulation check (which was used at the end of the study), participants reported that they had particular difficulty in determining/classifying the neutral photograph. Another reason that there is no difference in remembering central and peripheral details between positive and neutral events could be due to the nature of the positive photograph that we used (i.e., a newborn happiness in the family). Perhaps this theme may not have created enough positive emotions to the participants given they were young male university students. Especially in the studies conducted in laboratory environment, it is harder to elicit positive emotions than negative emotions to participants. Also in this study, despite the fact that positive photograph have been evaluated as such, they were not evaluated as marked as the respective negative photographs.

To conclude, the findings of our study have shown, similar to prior studies, that central details of negative emotional events are remembered better than positive ones (Kensinger et al., 2007b; Kensinger, 2009; Yegiyan and Lang, 2010; Yegiyan and Yonelinas, 2011; Chipchase and Chapman, 2013), but contradicts other studies which claim that positive emotions enhance remembering
(D'Argembeaue et al., 2003; Comblain et al., 2005; Kensinger and Schacter, 2006; Yegiyan and Yonelinas, 2011; Chipchase and Chapman, 2013).

Researches in many different domains including attention, learning, memory, judgement and decision-making, impression formation, and social interaction indicate that there is a bias towards to negative information or stimulus. According to this "negativity bias" negative stimulus or information have greater impact on general cognitive processes than positive or neutral ones even if when they have equal intensity (Jordan, 1965; Fiske, 1980; Peeters and Czapinski, 1990; Taylor, 1991; Ito, Larsen, Smith and Cacioppo, 1998; Baumeister, Bratslavsky, Finkenauer and Vohs, 2001; Rozin and Royzman, 2001). The findings of our study have supported the negativity bias. Additionally, findings that the young male university students remember better central and peripheral details of negative emotional event, is also consistent with findings which have shown that young people tend to remember negative stimuli better, while elderly people tend to remember better the positive ones (Charles, Mather and Carstensen, 2003; Kensinger, Garoff-Eaton and Schacter, 2007a; Langeslag and Strien, 2009).

The findings of our study is also consistent with the eye-tracking studies. According to eye-tracking studies, participants looked longer at emotional pictures than neutral ones (Calvo and Lang, 2004; Nummenmaa, Hynönä and Calvo, 2006; Chipchase and Chapman, 2013). However, there are two conflicting findings for positive and negative photographs. While Chipchase and Chapman (2013) indicated that negative pictures are longer viewed than positive ones, Humphreys, Underwood and Chapman (2010) indicated that positive pictures are longer viewed than negative ones. In our study, participants looked longer and more frequently to central details of positive event than negative and neutral ones. In this regard, the findings of our study is consistent with Humphreys, Underwood and Chapman's (2010) results, but it contradicts studies which show that viewers looked longer at central details of negative emotional events than neutral ones.

According to attentional narrowing hypothesis, arousal in negative emotional event directs the attention to central rather than to the peripheral characteristics of an event and for this reason the central details of an event are remembered better than the peripheral details (Safer et al, 1998; Wessel et al., 2000; Brown, 2003; Blank, 2011; Riggs et al., 2011) These results were supported by eye- 
tracking studies (Loftus et al., 1987; Christianson et al, 1991; Wessel et al., 2000; White, 2007; Blank, 2011; Chipchase and Chapman, 2013). However, there are contradictory findings about remembering peripheral details of emotional events. Although it has been shown that negative emotions reduce people's capacity to remember peripheral details (Loftus et al., 1987; Christianson and Loftus, 1991; Burke et al., 1992; Berntsen, 2002; Brown, 2003; Hope and Wright, 2007; Kensinger et al., 2007b; Kensinger, 2009; Talarico et al., 2009; Yegiyan and Yonelinas, 2011; Chipchase and Chapman, 2013), there are studies which have shown that negative emotions increase remembering of both central and peripheral details (Heuer and Reisberg 1990; Libkuman et al., 1999; Laney et al., 2004; Lanciano and Curci, 2011) and other studies which have shown that negative emotions make no difference in remembering peripheral details (Christianson et al, 1991; Wessel et al., 2000; Otani et al., 2007). While the findings of our study contradict to studies claiming that negative emotions reduce the possibility of remembering peripheral details, they are also supporting the studies which claim that negative emotions also increase remembering of peripheral details as central details.

One of the reasons of obtaining different results in remembering the peripheral details in the negative emotional event could be due to the difference in the level of emotional stimulus' arousal. As a matter of fact, according to Yegiyan and Lang (2010) the remembering of peripheral details depends on the arousal level of emotional stimulus. As the arousal increases up to a certain level so does the remembering of peripheral details. However, after that level remembering of peripheral details decrease. Therefore, studies obtaining different results in the effect of negative emotions on peripheral details may be due to the different arousal level of stimulus that they have used. In this study arousal level of photographs was not controlled. Therefore, this was one of the limitations of our study.

In addition, the definition of "peripheral detail" is not clear, while the number of questions and the duration of the tests differ among the studies. These factors could also be responsible for the different results. For example, in the study conducted by Christianson and Loftus (1991) objects having no connection with emotional event and away from focus point spatially was determined as "peripheral detail", whereas only one question about central and peripheral detail was asked. Nonetheless, in the study conducted by Heuer and Reisberg (1990) a gist-based approach was used in defining central and peripheral details: Elements closely related to the gist of emotional event were defined as central detail, while elements which were not directly related to emotional event were defined as peripheral detail; also, 10 questions were asked for each photograph's central and peripheral details. In this study, Heuer and Reisberg's approach was adopted in defining central and peripheral details and first-degree elements that were related to the emotional event were determined as central detail in the target photograph, while elements which were not directly related to the emotional event were determined as peripheral detail. Also, similar to Heuer and Reisberg's study, 10 questions for central details and 10 questions for peripheral details in target photographs were asked.

Another reason of obtaining different results in remembering the peripheral details about the negative emotional event could be attributed to the difference in the duration of displaying the photographs. For instance, in the study conducted by Christianson and Loftus (1991) photographs remained on the screen for 3 seconds, in the study conducted by Heuer and Reisberg (1990) for 6 seconds, and in this study for 8 seconds. This longer period on the screen may have contributed to better recall of peripheral details.

In conclusion, in our study same results were obtained with that reported in Heuer and Reisberg's (1990) study. This finding supports our view that conflicting results in remembering peripheral details in studies of event memory can be caused by methodological differences.

In eye-tracking studies it has been seen that attention gets narrow in negative emotional events (Loftus et al., 1987; Christianson et al, 1991; Wessel et al., 2000; White, 2007; Blank, 2011; Chipchase and Chapman, 2013). Also in our study, the total fixation duration on peripheral details in negative event was shorter than neutral event, although it did not reach statistical significance level. On the other hand, in terms of the total fixation duration on peripheral details, there was statistically significant difference between negative and positive event. The total fixation duration on peripheral details was longer in the positive event as compared to the negative event. Looking for a shorter time to peripheral details in a negative event than in a positive event is consistent with the results of study, which is about peripheral details attracting less attention in negative events.

Although there are studies showing that positive emotions extend the scope of attention (Fredrickson, 1998; 
Fredrickson and Branigan, 2005) and enhance remembering of peripheral details in positive emotional events (Talarico et al., 2009; Yegiyan and Lang, 2010; Yegiyan and Yonelinas, 2011), there are few studies, which have compared eye movements that are made to peripheral details of positive and negative events. Eye-tracking findings of our study, showed that participants looked longer and more frequently to peripheral details in positive event condition than participants in the negative and neutral event condition, and are consistent with studies, which have shown that peripheral details of positive stimulus took more fixation than peripheral details in negative or neutral stimulus (Wadlinger and Isaacowitz, 2006). Also, the findings of the present study is consistent with studies which claim that positive emotions extend the scope of attention (Fredrickson, 1998; Fredrickson and Branigan, 2005). It is seen that the results of our study support broaden-and-built hypothesis (Fredrickson, 1998), which claims that the scope of attention, as assessed through eye-tracking, extends in positive stimulus or events.

Some of the eye-tracking studies show that eye movements pattern could also differ between animate and inanimate objects (Kovic, Plunkett and Westermann, 2009; Carniglia, Caputi, Manfredi, Zambarbieri and Pessa, 2012). According to these studies, participants look for a shorter time and made less fixations to inanimate objects than to animate objects. In this study, the differences between animate and inanimate objects in central and peripheral AOIs of target photographs were tried to balanced as possible in the three emotional conditions. In other words, characters in central and peripheral AOIs were insofar as balanced both in negative and positive target photographs. But in neutral photograph it was not enough, since there was no emotional priority among characters; so all characters were defined as central AOIs while inanimate objects were defined as peripheral AOIs. For that reason, there was an animate-inanimate difference between central and peripheral AOIs in neutral target photograph. But it was not valid for negative and positive target photographs. So that, we redefine the AOIs and reanalyze the data by comparing eye movement patterns between people (animates) who participate in the central emotional event and people (animates) in the more peripheral locations in neutral target photograph. We defined young guy who is main character as central detail while we defined other characters as peripheral details. Then we made an additional statistical analysis for this new configuration. These findings showed that differences between animates in central AOIs (sequentially; for fixation duration $\mathrm{M}=4.47, \mathrm{SD}=4.19$; for fixation count $\mathrm{M}=8.85, \mathrm{SD}=6.05$ ) and animates in peripheral AOIs (sequentially; for fixation duration $\mathrm{M}=6.76$, $\mathrm{SD}=1.93$; for fixation count $\mathrm{M}=23.33, \mathrm{SD}=8.87$ ) were significant for all eye-tracking parameters (sequentially; for fixation duration $\mathrm{t}(27)=-2.64, \mathrm{p}<.05$; for fixation count $\mathrm{t}(27)=-6.59, \mathrm{p}<.001)$. In this way, when the animateinanimate status keeping fix on the single level (only animate), there was difference between central and peripheral details for eye-tracking parameters in the neutral target photograph. Therefore, differences in animate and inanimate objects between central and peripheral AOIs in neutral target photograph were another limitations of our study.

\section{Discussion Related with Effects of Perspective}

In our study, it was found that participants in the "own perspective" condition remembered central details better than participants in the "observer" condition. This finding shows that participants' perspective has an effect on event memory, similar to autobiographical memory studies (Nigro and Neisser, 1983; D'Argembeau et al., 2003; Berntsen and Rubin, 2006; Sayar and Cangöz, 2013).

Studies using words (Rogers et al., 1977; Symons and Johnson, 1997) and object photographs (Serbun, 2009) have shown that people tend to remember events better when they associate the event with themselves than when they associate the events with others or when the events are generally encoded. In our study, in which photograph series were used, it was found that participants who associated the event with themselves remembered central details better than the ones who looked at the photographs as an observer. In this aspect, in our study it was shown that the self-reference effect is also valid for thematic photograph series, which has high external validity.

In our study, the findings that participants' perspective are effective in remembering central details but not peripheral details can be explained by the fact that peripheral details are less related to an emotional event that is encoded as faint and weak.

In addition to the effects of participants' perspective on memory, it is seen that it is also effective on eye-track measurements. It has not been found in any of the studies, which investigate the effect of participants' perspective on memory through eye-tracking measurement. In our study, 
it was seen that participants in the "own perspective" condition looked longer at the central details of the event, while participants in the "observer" condition looked longer at the peripheral details of the event. These findings indicate that looking with one's own perspective at an event causes narrowing of attention, while looking with an observer's perspective to an event causes attention broadening. Besides the effect of participants' perspective on memory measurements, showing the effect of participants' perspective on eye-tracking measurements, is a unique aspect of this study.

In our study, it is seen that remembering the central details of events differs as a function of the emotional content of the event and participants' perspective. Thus, remembering the details of positive event depended on participants' perspective, but there was no difference either for negative or neutral event. Studies on autobiographical memory, flash memory or eyewitness memory have indicated that central details about the event are remembered better even if this event is an event the person experienced or an event that $\mathrm{s} / \mathrm{he}$ witnessed as an outsider observer (Christianson and Loftus, 1991; Burke, Heuer and Reisberg, 1992; Christianson and Hübinette, 1993; Wessel, Kooy and Merckelbach, 2000; Berntsen, 2002; Brown, 2003; D'Argembeau, Comblain and Linden, 2003; Kensinger, Krendl and Corkin, 2006; Kensinger and Schacter, 2006). Therefore, it can be said that negative emotional events affect everyone who experiences or observes an event. Evolutional importance of negative stimulus about threat and danger and their relation to survival may be important in remembering central details related to negative emotional events better in every circumstances. No difference based on participant perspective in remembering central details of neutral events may be due to the fact that neutral events are coded less vivid and detailed than emotional events. About peripheral details, the fact that these details are remembered harder due to their weaker relation to the emotional event may have caused participants to show similar performances in both the "own perspective" and the "observer" perspective and in both emotional and neutral events independently of emotional content of the event.

Similar to the observed differences in remembering central details in positive emotional event as a function of participants' perspective, there were differences in eyetracking as a function of participants' perspective in posi- tive emotional event. Specifically, in the positive emotional event, participants in the "own perspective" condition looked at central details longer than their counterparts in the observer perspective condition. However, no difference was found in perspective taking either in the negative and neutral event conditions.

\section{General Discussion}

When free recall and eye-tracking findings are evaluated together, some important clues arise about the relationship of emotion, attention and memory. It was seen that central and peripheral details in negative and neutral event conditions took almost equal number of fixations. However, central and peripheral details in the negative event condition were remembered better than the details in the neutral event condition. As a result, although central and peripheral details took equal attention in both emotional events, only details of the negative event were better remembered. On the other hand, although there were longer and more fixations in central as well as in peripheral details in the positive than the negative or the neutral event condition, a memory enhancement effect was occurred only in the negative event condition; in other words, only details of negative event were remembered better. On that sense, the results of our study support the studies which suggest that attention by itself is not enough in explaining differences in the remembering emotional events and that emotion is also an important factor (Christianson et al, 1991; Humphreys, Underwood and Chapman, 2010; Riggs et al., 2011). In brief, it is shown that (1) perspective taking have an effect on attention as well as on event memory; (2) attention is not sufficient by itself to remember an event with details; emotional dimension of the event has a decisive role. This seems particularly true in negative events, as such events are considered important in terms of evolution because they have a direct impact on memory through brain structures such as the amygdala (Buchanan and Adolphs, 2002). So, negative events has a superiority to remember, even the differences in distribution of overt attention; (3) regarding negative emotions, the memory enhancement effect is independent of the attention; (4) memory was better in negative events, while attention (as assessed through eye-tracking) was superior in positive events and (5) because the negative emotional events are encoded in a more vivid and detailed manner, they are better remembered. 
Appendix 1

THEMATIC PHOTOGRAPH SERIES
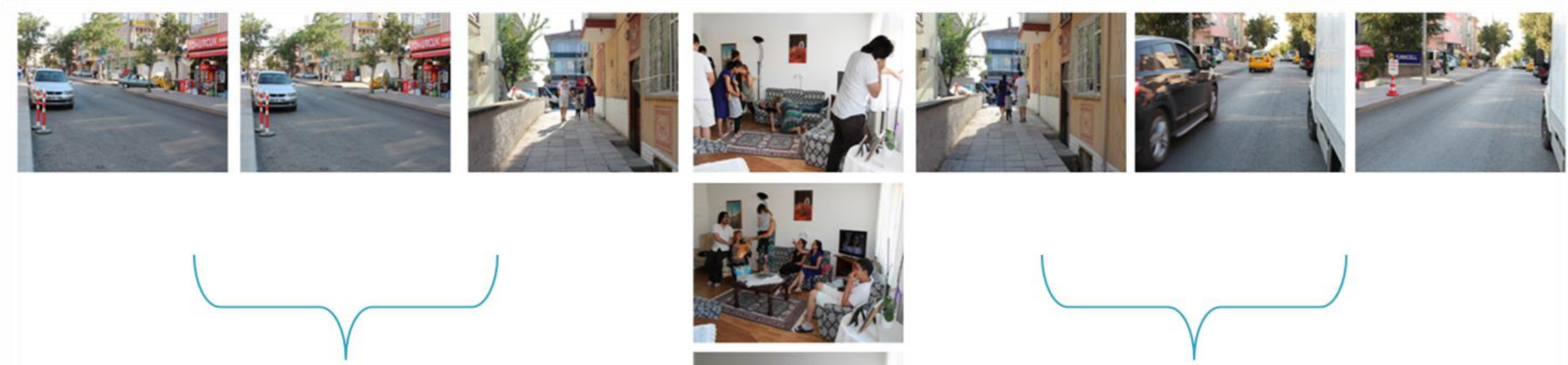

same in 3 series
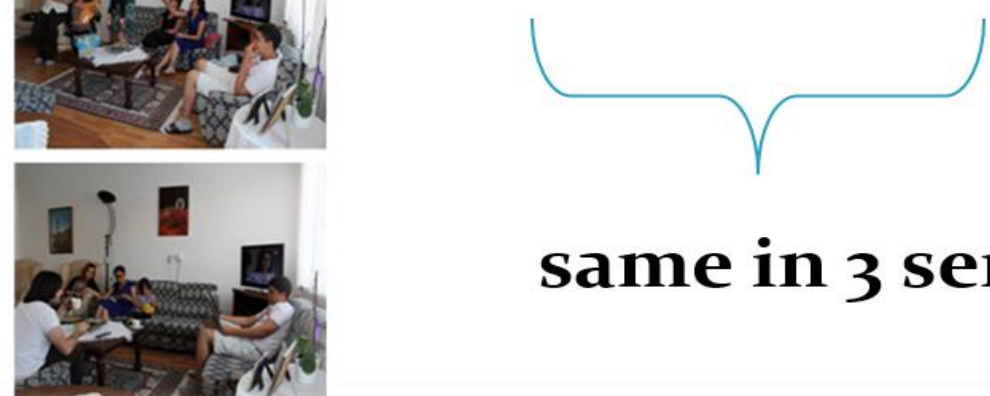

\section{same in 3 series}

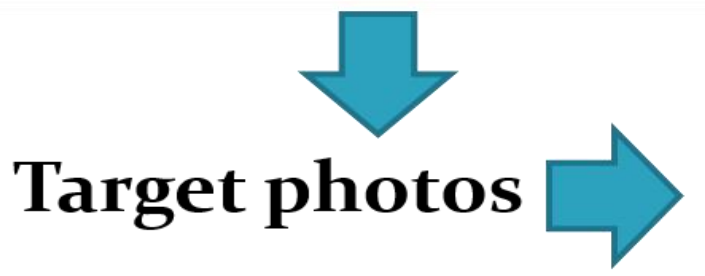

Negative $\rightarrow$ Death

Positive $\rightarrow$ Birth

Neutral $\rightarrow$ Everyday home

state 
Journal of Eye Movement Research $9(2): 4,1-19$

Appendix 2. Heat Maps (Total Fixation Counts) of Target Photographs for Each Emotional Events

Observer

Perspective

Own

Perspective
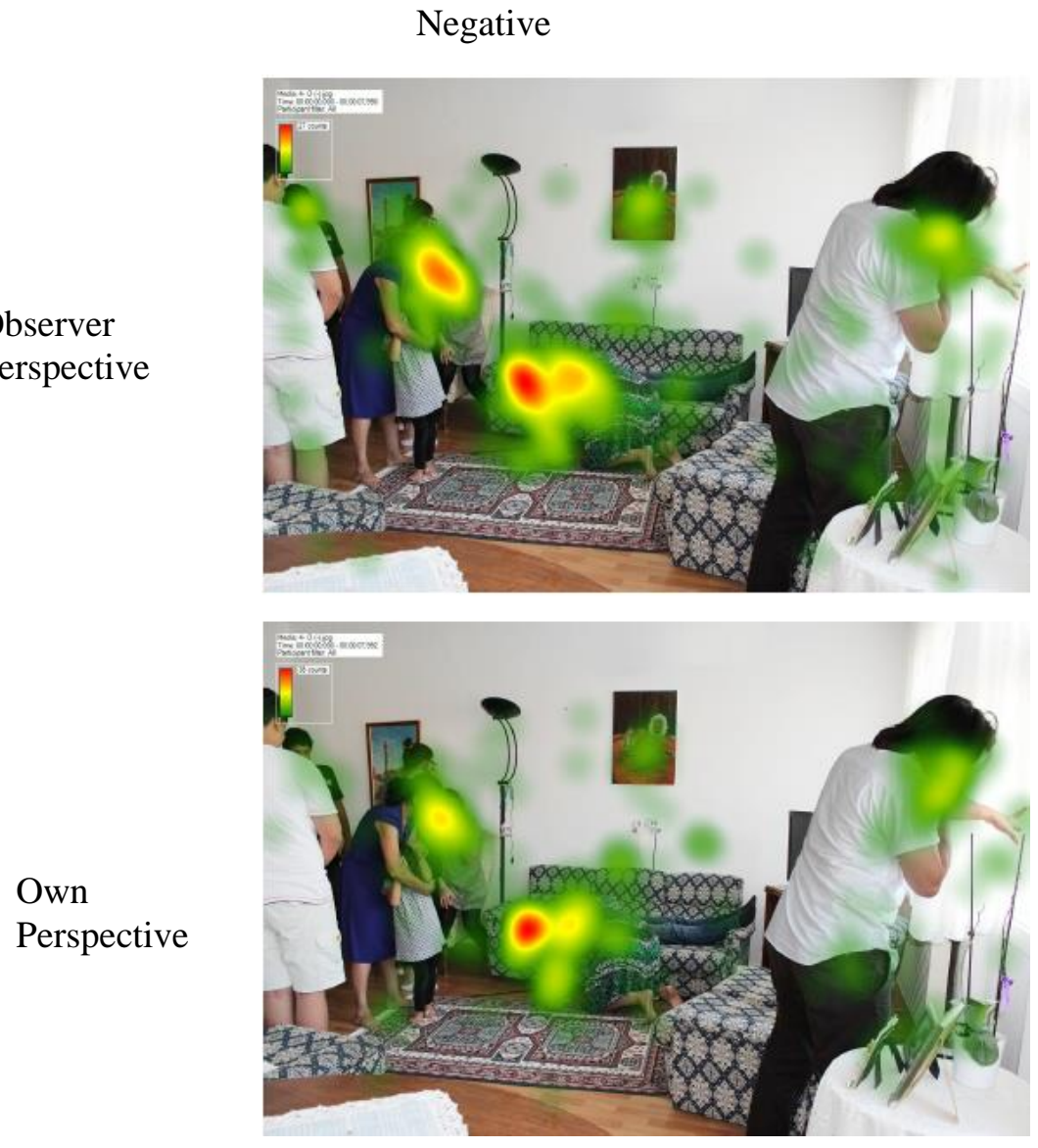

Emotional Content of Event

Positive
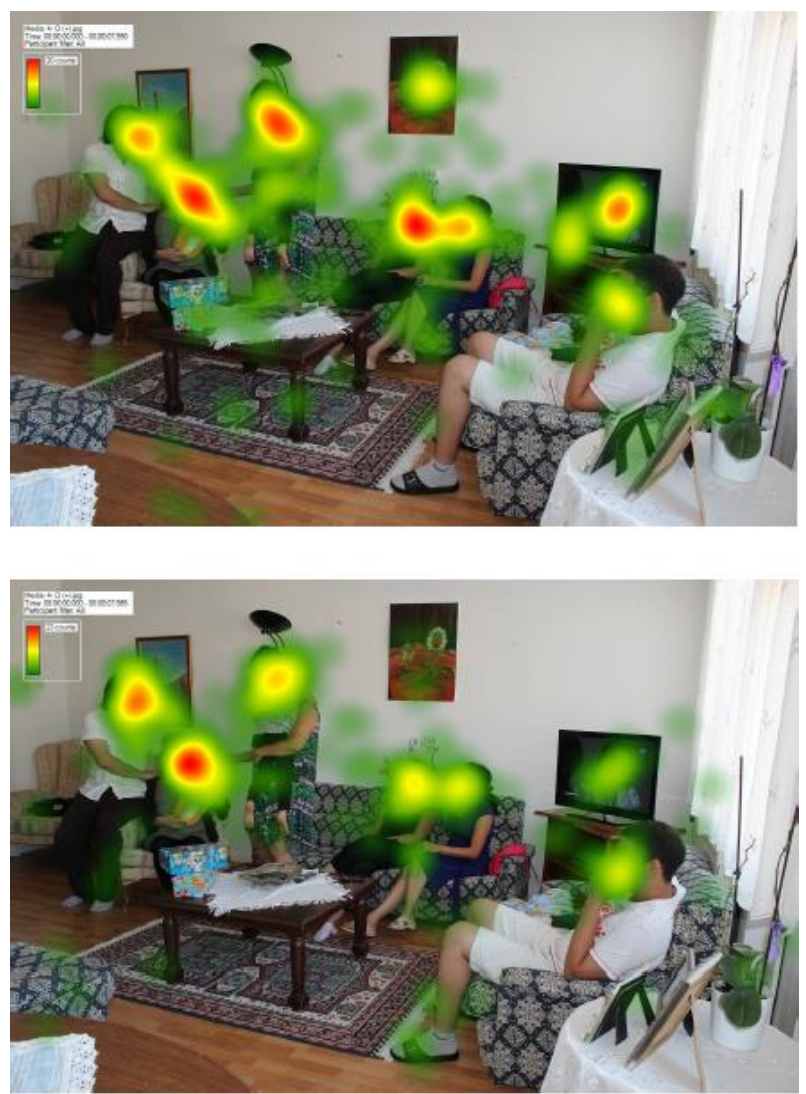

14
Gülçay, C. \& Cangöz B. (2016) Effects of Emotion and Perspective on Remembering Events An Eye-Tracking Study
Neutral
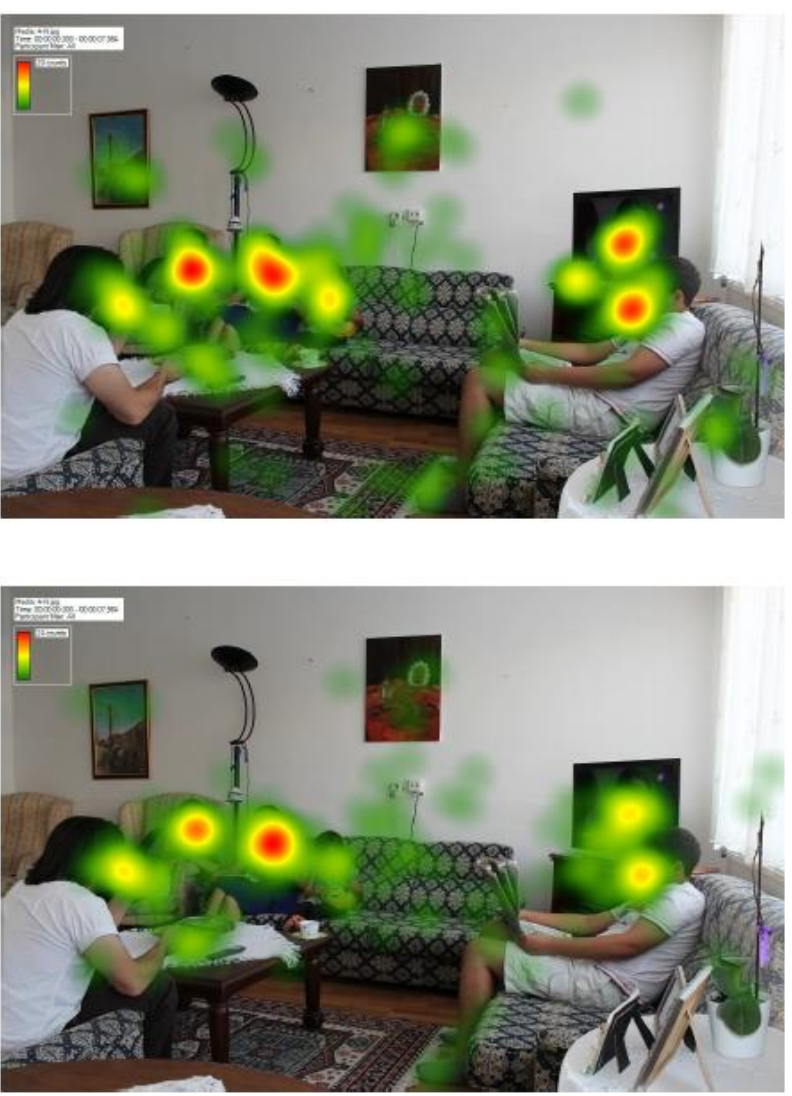
Appendix 3

Example Questions of Free Recall Forms

\begin{tabular}{|c|c|c|}
\hline Emotional Events & Central Details & Peripheral Details \\
\hline Negative Event & $\begin{array}{l}\text { 1) What was the color of the t-shirt of drug } \\
\text { addicted young man in the target photo- } \\
\text { graph? } \\
\text { 2) What was the healthy young man doing } \\
\text { in the target photograph? } \\
\text { 3) How many people were there in the } \\
\text { room in the target photograph? } \\
\text { 4) Was there anything in the hands of the } \\
\text { drug-addicted young man in the target } \\
\text { photograph? }\end{array}$ & $\begin{array}{l}\text { 1) How many pictures were there on the } \\
\text { wall in the target photograph? } \\
\text { 2) What was the color of the wall in the } \\
\text { target photograph? } \\
\text { 3) How many people were there talking } \\
\text { to a mobile phone in the target photo- } \\
\text { graph? } \\
\text { 4) What was the hair length of the person } \\
\text { closest to drug addicted young man in } \\
\text { the target photograph? }\end{array}$ \\
\hline Positive Event & $\begin{array}{l}\text { 1) What was the young man doing in the } \\
\text { target photograph? } \\
\text { 2) What was the gender of the person hold- } \\
\text { ing the baby in her/his arms in the target } \\
\text { photograph? } \\
\text { 3) What was the color of young man's } \\
\text { shirt in the target photograph? } \\
\text { 4) What was the color of the babygro in } \\
\text { the target photograph? }\end{array}$ & $\begin{array}{l}\text { 1) How many pictures were there on the } \\
\text { wall in the target photograph? } \\
\text { 2) How many gifts were there on the ta- } \\
\text { ble in the target photograph? } \\
\text { 3) What was the color of the little girl's } \\
\text { trousers in the target photograph? } \\
\text { 4) What was the hair color of the person } \\
\text { who is holding the baby in her/his arms } \\
\text { in the target photograph? }\end{array}$ \\
\hline Neutral Event & $\begin{array}{l}\text { 1) What was the young man doing in the } \\
\text { target photograph? } \\
\text { 2) How many people were there in the } \\
\text { room in the target photograph? } \\
\text { 3) Who was sitting next to the little child } \\
\text { in the target photograph? } \\
\text { 4) What was in the hands of the young } \\
\text { man in the target photograph? }\end{array}$ & $\begin{array}{l}\text { 1) How many pictures were there on the } \\
\text { wall in the target photograph? } \\
\text { 2) What was the hair color of young } \\
\text { woman in the target photograph? } \\
\text { 3) What was the color of the adult } \\
\text { woman's dress in the target photograph? } \\
\text { 4) What was the color of the little child's } \\
\text { toy in the target photograph? }\end{array}$ \\
\hline
\end{tabular}




\section{Appendix 4}

\section{Questionnaires For Manipulation Check}

\begin{tabular}{|c|c|}
\hline Emotional Content of Event & $\begin{array}{l}\text { 1) What is the basic emotion in the target photograph according to you? } \\
\text { Please describe. } \\
\text { 2) Do you think target photograph includes positive / negative / neutral emo- } \\
\text { tion? Please describe. } \\
\text { 3) What would you suggest for target photograph to include more positive / } \\
\text { negative / neutral emotion? }\end{array}$ \\
\hline Participants' Perspective & $\begin{array}{l}\text { 1) Did you empathize/associate yourself with the main character when you } \\
\text { were watching thematic photograph series? Were you able to feel that the } \\
\text { situation in the photograph was like an event that happened to you? Please } \\
\text { describe. } \\
\text { 2) How much were you successful at empathizing/associating yourself with } \\
\text { the main character? Please describe. } \\
\text { 3) What would you suggest for target photograph to be more successful em- } \\
\text { pathizing/associating yourself with the main character? }\end{array}$ \\
\hline
\end{tabular}




\section{References}

Baran, Z., Cangöz, B. \& Özel-Kızıl, T. (2014). The impact of aging and Alzheimer's disease on emotional enhancement of memory. European Neurology, 72, 30-37. doi:10.1159/000359924

Baumeister, R. F., Bratslavsky, E., Finkenauer, C., \& Vohs, K. D. (2001). Bad is stronger than good. Review of General Psychology, 5(4), 323. doi:10.1037/1089-2680.5.4.323

Berntsen, D. (2002). Tunnel memories for autobiographical events: Central details are remembered more frequently from shocking than from happy experiences. Memory \& Cognition, 30(7), 1010-1020. doi:10.3758/BF03194319

Berntsen, D. \& Rubin, D. C. (2006). Emotion and vantage point in autobiographical. Cognition and Emotion, 20(8), 1193-1215. doi:10.1080/02699930500371190

Birch J. (1997). Efficiency of the Ishihara test for identifying red-green colour deficiency. Ophthalmic and Physiological Optics 17(5): 403-408. doi:10.1046/j.1475-1313.1997.97000227.x

Blank, M. P. (2011). Allocation of Attention and the Encoding of Emotional Memories. Doctoral dissertation, University of Minnesota, US. http://purl.umn.edu/112939

Brown, J. M. (2003). Eyewitness memory for arousing events: Putting things into context. Applied Cognitive Psychology, 17(1), 93-106. doi:10.1002/acp.848

Buchanan, T.W. (2007). Retrieval of emotional memories. Psychological Bulletin, 133(5), 761-779. doi:10.1037/0033-2909.133.5.761

Buchanan, T.W. \& Adolphs, R. (2002). The role of the human amygdala in emotional modulation of longterm declarative memory. In S. Moore \& M. Oaksford (Eds.), Emotional Cognition: From Brain to Behavior (pp. 9-34). London: Benjamins.

Burke, A., Heuer, F. \& Reisberg, D. (1992). Remembering emotional events. Memory \& Cognition, 20(3), 277-290. doi:10.3758/BF03199665

Calvo, M. G. \& Lang, P. J. (2004). Gaze patterns when looking at emotional pictures: Motivationally biased attention. Motivation and Emotion, 28(3), 221-243. doi:10.1023/B:MOEM.0000040153.26156.ed
Carniglia, E., Caputi, M., Manfredi, V., Zambarbieri, D., \& Pessa, E. (2012). The influence of emotional picture thematic content on exploratory eye movements. Journal of Eye Movement Research, 5(4), 4.

Charles, S. T., Mather, M. \& Carstensen, L. L. (2003). Aging and emotional memory: the forgettable nature of negative images for older adults. Journal of Experimental Psychology: General, 132(2), 310. doi:10.1037/0096-3445.132.2.310.

Chipchase, S.Y. \& Chapman, P. (2013). Trade-offs in visual attention and the enhancement of memory specificity for positive and negative emotional stimuli. The Quarterly Journal of Experimental Psychology, 66(2), 277-298.

doi:10.1080/17470218.2012.707664

Christianson, S. Å. (1992). Emotional stress and eyewitness memory: A critical review. Psychological Bulletin, 112(2), 284. doi:10.1037/0033-2909.112.2.284

Christianson, S. Å. \& Loftus, E. F. (1991). Remembering emotional events: The fate of detailed information. Cognition \& Emotion, 5(2), 81-108. doi:10.1080/02699939108411027

Christianson, S. A., Loftus, E. F., Hoffman, H. \& Loftus, G. R. (1991). Eye fixations and memory for emotional events. Journal of Experimental Psychology: Learning, Memory, and Cognition, 17(4), 693-701. doi:10.1037/0278-7393.17.4.693

Comblain, C., D'Argembeau, A. \& Linden, M. (2005). Phenomenal characteristics of autobiographical memories for emotional and neutral events in older and younger adults. Experimental Aging Research, 31(2), 173-189. doi:10.1080/03610730590915010

Conway, M. A. (1996). Autobiographical memory. In E. L. Bjork, R. A. Bjork (Eds), Handbook of Perception and Cognition: Memory (pp. 165-194). Academic Press: San Diego, CA.

D'Argembeau, A., Comblain, C. \& Linden, M.(2003). Phenomenal characteristics of autobiographical memories for positive, negative, and neutral events. Applied Cognitive Psychology, 17(3), 281-294. doi:10.1002/acp.856

Fiske, S. T. (1980). Attention and weight in person perception: The impact of negative and extreme behavior. Journal of Personality and Social Psychology, 38(6), 889-906. doi:10.1037/0022-3514.38.6.889 
Fredrickson, B. L. (1998). What good are positive emotions?. Review of General Psychology, 2(3), 300. doi:10.1037/1089-2680.2.3.300

Fredrickson, B. L. \& Branigan, C. (2005). Positive emotions broaden the scope of attention and thought-action repertoires. Cognition \& Emotion, 19(3), 313332. doi:10.1080/02699930441000238

Hamann, S. (2001). Cognitive and neural mechanisms of emotional memory. Trends in Cognitive Sciences, 5(9), 394-400. doi:10.1016/S1364-6613(00)01707-1

Heuer, F. \& Reisberg, D. (1990). Vivid memories of emotional events: The accuracy of remembered minutiae. Memory \& Cognition, 18(5), 496-506. doi:10.3758/BF03198482

Hope, L. \& Wright, D. (2007). Beyond unusual? Examining the role of attention in the weapon focus effect. Applied Cognitive Psychology, 21(7), 951-961. doi:10.1002/acp.1307

Humphreys, L., Underwood, G. \& Chapman, P. (2010). Enhanced memory for emotional pictures: A product of increased attention to affective stimuli? European Journal of Cognitive Psychology, 22(8), 1235-1247. doi:10.1080/09541440903427487

Ishihara S. (1990). Ishihara's Tests For Colour-Blindness 38 Plates Edition. Tokyo Kyoto.

Ito, T. A., Larsen, J. T., Smith, N. K., \& Cacioppo, J. T. (1998). Negative information weighs more heavily on the brain: the negativity bias in evaluative categorizations. Journal of Personality and Social Psychology, 75(4), 887. doi:10.1037/0022-3514.75.4.887

Jordan, N. (1965). The" asymmetry" of" liking" and" disliking": A phenomenon meriting further reflection and research. Public Opinion Quarterly, 315-322. doi:10.1086/267327

Kensinger, E. A. (2009). Remembering the details: Effects of emotion. Emotion Review, 1(2), 99-113. doi:10.1177/1754073908100432

Kensinger, E. A. \& Schacter, D. L. (2006). When the Red Sox shocked the Yankees: Comparing negative and positive memories. Psychonomic Bulletin \& Review, 13(5), 757-763. doi:10.3758/BF03193993
Kensinger, E. A., Garoff-Eaton, R. J. \& Schacter, D. L. (2007a). Effects of emotion on memory specificity in young and older adults. The Journals of Gerontology Series B: Psychological Sciences and Social Sciences, 62(4), 208-215.

Kensinger, E. A., Garoff-Eaton, R. J. \& Schacter, D. L. (2007b). Effects of emotion on memory specificity: Memory trade-offs elicited by negative visually arousing stimuli. Journal of Memory and Language, 56(4), 575-591. doi:10.1016/j.jml.2006.05.004

Kensinger, E. A., Krendl, A. C. \& Corkin, S. (2006). Memories of an emotional and a nonemotional event: Effects of aging and delay interval. Experimental Aging Research, 32(1), 23-45. doi:10.1080/01902140500325031

Ković, V., Plunkett, K., \& Westermann, G. (2009). Eyetracking study of inanimate objects. Psihologija, 42(4), 417-436. doi:10.2298/PSI0904417K

Lanciano, T. \& Curci, A. (2011). Memory for emotional events: The accuracy of central and peripheral details. Europe's Journal of Psychology, 7(2), 323-336.

Laney, C., Campbell, H. V., Heuer, F. \& Reisberg, D. (2004). Memory for thematically arousing events. Memory \& Cognition, 32(7), 1149-1159. doi: 10.3758/BF03196888

Langeslag, S. J. \& van Strien, J. W. (2009). Aging and emotional memory: the co-occurrence of neurophysiological and behavioral positivity effects. Emotion, 9(3), 369. doi:10.1037/a0015356

Libkuman, T. M., Nichols-Whitehead, P., Griffith, J. \& Thomas, R. (1999). Source of arousal and memory for detail. Memory \& Cognition, 27(1), 166-190. doi:10.3758/BF03201222

Libkuman, T., Stabler, C. \& Otani, H. (2004). Arousal, valence, and memory for detail. Memory, 12(2), 237247. doi:10.1080/09658210244000630

Loftus, G. R. (1972). Eye fixations and recognition memory for pictures. Cognitive Psychology, 3(4), 525-551. doi:10.1016/0010-0285(72)90021-7

Loftus, E. F. \& Burns, T. E. (1982). Mental shock can produce retrograde amnesia. Memory \& Cognition, 10(4), 318-323. doi:10.3758/BF03202423

Loftus, E. F., Loftus, G. R. \& Messo, J. (1987). Some facts about "weapon focus". Law and Human Behavior, 11(1), 55-62. doi:10.1007/BF01044839 
Nigro, G. \& Neisser, U. (1983). Point of view in personal memories. Cognitive Psychology, 15(4), 467-482. doi:10.1016/0010-0285(83)90016-6

Nummenmaa, L., Hyönä, J. \& Calvo, M. G. (2006). Eye movement assessment of selective attentional capture by emotional pictures. Emotion, 6(2), 257-268. doi:10.1037/1528-3542.6.2.257

Otani, H., Libkuman, T. M., Widner, R. L. \& Graves, E. I. (2007). Memory for emotionally arousing stimuli: A comparison of younger and older adults. The Journal of General Psychology, 134(1), 23-42. doi:10.3200/GENP.134.1.23-42

Peeters, G., \& Czapinski, J. (1990). Positive-negative asymmetry in evaluations: The distinction between affective and informational negativity effects. European Review of Social Psychology, 1(1), 33-60. doi:10.1080/14792779108401856

Riggs, L., McQuiggan, D. A., Farb, N., Anderson, A. K. \& Ryan, J. D. (2011). The role of overt attention in emotion-modulated memory. Emotion, 11(4), 776785. doi:10.1037/a0022591

Rogers, T. B., Kuiper, N. A. \& Kirker, W. S. (1977). Self-reference and the encoding of personal information. Journal of Personality and Social Psychology, 35(9), 677-688. doi:10.1037/0022-3514.35.9.677

Rozin, P. \& Royzman, E.B. (2001). Negativity bias, negativity dominance, and cognition. Personality and Social Psychology Review, 5(4), 296-320. doi:10.1207/S15327957PSPR0504_2

Safer, M. A., Christianson, S. Å., Autry, M. W. \& Österlund, K. (1998). Tunnel memory for traumatic events. Applied Cognitive Psychology, 12(2), 99-117. doi:10.1002/(SICI)1099-0720(199804)12:2<99::AIDACP509>3.0.CO;2-7

Sayar, F. \& Cangöz, B. (2013). Genç ve yaşıı bireylerin duygusal bellek işlevleri açısından karşılaştırılması. Turkish Journal of Geriatrics, 16(2), 177-184.

Serbun, S.J. (2009). Memory for object details in selfand other-referencing. Master's Thesis. Brandeis University, US. http://hdl.handle.net/10192/23325

Symons, C. S. \& Johnson, B. T. (1997). The self-reference effect in memory: A meta-analysis. Psychological Bulletin, 121(3), 371-394. doi:10.1037/00332909.121.3.371
Talarico, J. M., Berntsen, D. \& Rubin, D. C. (2009). Positive emotions enhance recall of peripheral details. Cognition and Emotion, 23(2), 380-398. doi:10.1080/02699930801993999

Taylor, S. E. (1991). Asymmetrical effects of positive and negative events: the mobilization-minimization hypothesis. Psychological Bulletin, 110(1), 67-85. doi:10.1037/0033-2909.110.1.67

Wadlinger, H. A. \& Isaacowitz, D. M. (2006). Positive mood broadens visual attention to positive stimuli. Motivation and Emotion, 30(1), 87-99. doi:10.1007/s11031-006-9021-1

Wessel, I., De Kooy, P. V. \& Merckelbach, H. (2000). Differential recall of central and peripheral details of emotional slides is not a stable phenomenon.

Memory, 8(2), 95-109. doi:10.1080/096582100387641

White, L. N. (2007). The Effects of Multidimensional Arousal and Thematically Induced Detail on Attention and Memory for an Emotional Event. Doctoral dissertation, Reed College, US.

Yegiyan, N. S. \& Lang, A. (2010). Processing central and peripheral detail: How content arousal and emotional tone influence encoding. Media Psychology,13(1), 7799. doi:10.1080/15213260903563014

Yegiyan, N. S. \& Yonelinas, A. P. (2011). Encoding details: positive emotion leads to memory broadening. Cognition \& Emotion, 25(7), 1255-62. doi:10.1080/02699931.2010.540821 